\title{
Teamwork in Health Care Services Delivery in Nigeria: A Mixed Methods Assessment of Perceptions and Lived Experiences of Pharmacists in a Tertiary Hospital
}

\author{
Elijah Mohammed (iD) ${ }^{1,2}$ \\ Warren G McDonald' \\ Adaobi C Ezike (iD ${ }^{3}$ \\ 'Department of Health Policy, Walden \\ University, Baltimore, MD, USA; \\ ${ }^{2}$ Department of Registry, Pharmacists \\ Council of Nigeria, Abuja, Nigeria; \\ ${ }^{3}$ Department of Pharmacology and \\ Toxicology, University of Nigeria, \\ Nsukka, Enugu State, Nigeria
}

Background: Lack of teamwork is the bane of weak and ineffective health care systems in many countries. This study examined the perceptions and lived experiences of pharmacists working in a Nigerian government-owned (public) multispecialty tertiary hospital regarding teamwork in their workplace.

Methods: A sequential explanatory mixed methods study using phenomenological approach of inquiry, was conducted among pharmacists with experience in multidisciplinary health care provision in a public tertiary hospital in Nigeria. Questionnaires with 16 close-ended questions based on a Likert scale, which scored from strongly disagree (1) to strongly agree (5), were administered. The mean (M) scores were determined using SPSS Version 20; $M \geq 3.00$ indicated agree, while $\mathrm{M}<3.00$ disagree. Subsequently, focus group discussions were conducted, and the audio recorded responses transcribed and subjected to thematic analysis using NVivo 11.

Results: Some participants (50\%) had worked for 5-10 years in the hospital's Department of Pharmacy, 25\% (11-20 years), and 16.7\% (21-30 years). Participants agreed that effective teamwork leads to positive patient outcomes $(M=3.67)$ and is in the public's interest $(M=$ 4.25). However, they disagreed that their workplace supports teamwork $(M=2.33)$, effective interprofessional collaborative practices exist in the hospital $(\mathrm{M}=1.08)$, and their remuneration reflects their worth to the organization $(\mathrm{M}=2.33)$. Doctors' dominance and claim of ownership of patients, allied professionals' attitudes and ignorance of pharmacists' roles, salary disparity, poor communication, and defective leadership style among others were identified as impediments to teamwork.

Conclusion: The hospital pharmacists demonstrated positive disposition towards teamwork, and agreed that effective teamwork would improve health care delivery. However, they identified some factors that hinder interprofessional teamwork in the hospital. Principles and practices of teamwork should be incorporated into the curriculum of each discipline; interdisciplinary collaborative practices, health system structure, institutional policies and leadership should be strengthened to enhance teamwork.

Keywords: attitudes of health care professionals, interprofessional collaboration, ownership of patients, interdisciplinary rivalry, turf protection, salary disparity

\section{Introduction}

Correspondence: Adaobi C Ezike Department of Pharmacology and Toxicology, University of Nigeria, Nsukka, 410001 , Enugu State, Nigeria

Tel +2348052820538

Email adaobi.ezike@unn.edu.ng
A team is a distinguishable set of two or more people who interact dynamically, interdependently, and adaptively towards a common and valued goal; who have been assigned specific roles or functions to perform; and have a limited lifespan of 
membership. ${ }^{1,2}$ Generally, health care providers are skilled human resources for health of diverse professions, age, educational and cultural backgrounds, who share an integrated goal - to provide positive patient outcomes. Provision of optimum health care involves the participation of diverse team members consisting of specialized health care professionals (doctors, laboratory scientists, nurses, pharmacists, physiotherapists, and others); other staff of the health facility; patients; and family. Globally, interdisciplinary health care teamwork is increasingly favored as a strategy to improve service delivery. ${ }^{3}$ Various studies have shown that effective teamwork in health care services delivery can significantly reduce medical errors and unnecessary wastes, improve efficiency, improve health outcomes and quality of care, enhance patient safety, improve patient satisfaction, reduce patient morbidity, reduce workloads, increase job satisfaction and retention, and strengthen health systems. ${ }^{2,4-6}$ Effective health care teamwork is beneficial to the patient, team members, the team, the health facility, and society at large; and is globally recognized as an essential tool for building and sustaining an optimum health care services delivery system. ${ }^{7}$

In Nigeria, pharmacists as medication specialists provide and evaluate much of the drug information used by doctors, nurses, and patients. The traditional roles of pharmacists primarily focused on dispensing, distribution and supply of medicines and other health products, while interaction with other health care professionals was somewhat limited. However, along with the health care needs of the population, the Nigerian pharmacist's role is expanding and evolving from the traditional product-oriented to include patient-oriented (clinical) functions. Currently in Nigeria as in other countries of the world, pharmacists perform patient-oriented, administrative and public health functions; such as counseling, education, preventive care, health screening and advocacy, among others. ${ }^{8,9}$ Pharmacists review prescriptions/medication orders, ensure the rational and cost-effective use of medicines, promote healthy living, and improve clinical outcomes by actively engaging in direct patient care and collaborating with other health care professionals. With this expanding scope of practice, pharmacists are being recognized globally as part of interprofessional health care teams for providing optimum patient care. ${ }^{10,11}$

It is well recognized that teamwork by health care professionals at their workplace is essential to achieve optimum health care services delivery, however its practical realization has been limited. ${ }^{3,12,13}$ Studies have demonstrated that lack of effective teamwork is the bane of weak and ineffective health care systems in many countries of the world, including Nigeria. ${ }^{14-17}$ Earlier studies revealed that the weak and suboptimal quality of health care services in Nigeria is partly attributable to lack of harmony and teamwork among professionals in the health sector, lack of skilled medical personnel and equipment, and underfunding among other factors. ${ }^{18-21}$

A tertiary hospital provides health care by specialists; consequently, there are health care professionals from various disciplines, viz doctors, pharmacists, nurses, radiologists, physiotherapists, and others. In an effort to better understand and proffer solutions to lack of teamwork among health care professionals in Nigeria, this study explored the perceptions and lived experiences of pharmacists working in a government-owned tertiary hospital about teamwork.

\section{Methods \\ Study Design}

The study was conducted using sequential explanatory strategy of mixed methods design, wherein quantitative data was collected and analyzed in the first phase followed by the collection and analysis of qualitative data in a second phase. ${ }^{22,23}$ Furthermore, the study adopted a phenomenological strategy of inquiry to explore and understand teamwork in the hospital, by using the participants' descriptions of their perceptions and lived experiences of workplace teamwork. Phenomenological research is a strategy of inquiry in which the researcher identifies the essence of human experiences about a phenomenon as described by participants (Creswell, 2009; 2013). ${ }^{23,24}$

\section{Study Setting}

The location of the study was the Pharmacy Department of a multispecialty tertiary hospital in Abuja, Nigeria, owned and managed by the Federal Government of Nigeria. The hospital provides health care by various professionals doctors, pharmacists, nurses, radiologists, physiotherapists, among others.

\section{Study Population and Sampling Strategy}

Purposive sampling using selected experiential pharmacists with relevant knowledge and experience in the phenomenon under study ${ }^{25,26}$ was utilized in the study. The study population used was all pharmacists (12) who had 
worked in the Pharmacy Department of the hospital for at least 5 years, were currently working or had worked in a team of not less than 10 members, and met all the inclusion criteria.

The pharmacists' training comprised a minimum qualification of Bachelor of Pharmacy (B. Pharm.) or Doctor of Pharmacy (Pharm. D.), and completion of the mandatory 1-year internship. The pharmacists were "hospital pharmacists" (ie, their practice area was hospital pharmacy) whose roles and responsibilities included pharmaceutical care for both outpatients and inpatients, including medication therapy management; drug procurement; filling of prescriptions and drug dispensing; compounding of extemporaneous preparations; patient education and counselling; provision of drug information services; and pharmacovigilance, among others.

\section{Inclusion Criteria}

Nigerian pharmacists who were fluent in English language; at least 28 years of age; worked in the study location for at least five years; knowledgeable in the study phenomenon (perceptions and lived experiences of the pharmacists regarding teamwork in the hospital), by virtue of at least 5 years working experience in the Department, so as to share empirical information; currently working or had worked in a multiprofessional team of not less than 10 members; and willing to participate in the study were included in the study. Volunteers that did not satisfy the inclusion criteria were excluded from the study.

\section{Data Collection Methods}

Data were collected as responses to close-ended questions and open-ended questions administered as questionnaires and during focus group discussions, respectively. The questions (which were structured to answer the research questions), covered perceptions and lived experiences of the pharmacists regarding teamwork, and barriers that influence teamwork in their workplace.

The quantitative phase of study involved administration of structured questionnaire divided into three sections to collect information on key components of the study phenomenon, namely: Section A - socio-demographic characteristics of the respondents, including years of work experience; Section B - awareness and perceived benefits of teamwork; Section $\mathrm{C}$ - factors that influenced teamwork in their workplace. Questions in Sections B and $\mathrm{C}$ were 16 close-ended questions with responses scored on a five-choice Likert scale. The five-choice Likert scale scored from (1) strongly disagree, (2) disagree, (3) neutral, (4) agree, to (5) strongly agree. The mean (M) and standard deviation (SD) of the responses were determined using SPSS (Version 20). The average of the five-point scale, $\mathrm{M}=3.00$ was used as a cut-off point; thus, $\mathrm{M}$ above 3.00 indicated agree, whereas below 3.00 disagree.

In the qualitative study, three separate focus group discussions involving 4 participants per session were used to gain insights into the respondents' perceptions and lived experiences of the phenomenon, using openended questions to guide the discussions. The focus group discussions were conducted by the researchers, and responses were audio recorded.

\section{Data Analysis}

The quantitative data were analyzed using SPSS (Version 20). The frequency and percent occurrence of respective socio-demographic characteristics were calculated. Also, the mean and standard deviation (SD) of the responses based on the five-choice Likert scale were calculated.

The audio recorded responses from the focus group discussions were transcribed accordingly. Subsequently, qualitative data were subjected to thematic analysis using the conceptual framework of belief system theory; this involved coding the data, organizing and categorizing the data under common themes and sub-themes, and interpretation. The NVivo 11 software was used for coding and categorizing the data. Findings of this study were discussed with the participants in a validation meeting.

\section{Results}

\section{Socio-Demographic Profile of the Participants}

An analysis of the socio-demographic profile of the participants showed that $83.3 \%$ had Bachelor of Pharmacy (B. Pharm.) degree as the highest professional educational qualification, while $16.7 \%$ had in addition Fellowship of West African Postgraduate College of Pharmacy (FPCPharm) (obtained after the first degree and some years of working experience). The results further showed that $41.7 \%$ had 11-30 years of work experience, while $50 \%$ and $8.3 \%$ had less than 10 years and over 30 years of experience, respectively; $91.7 \%$ were above 30 years of age; $58.3 \%$ are males while $41.7 \%$ are females (Figure 1). 
A

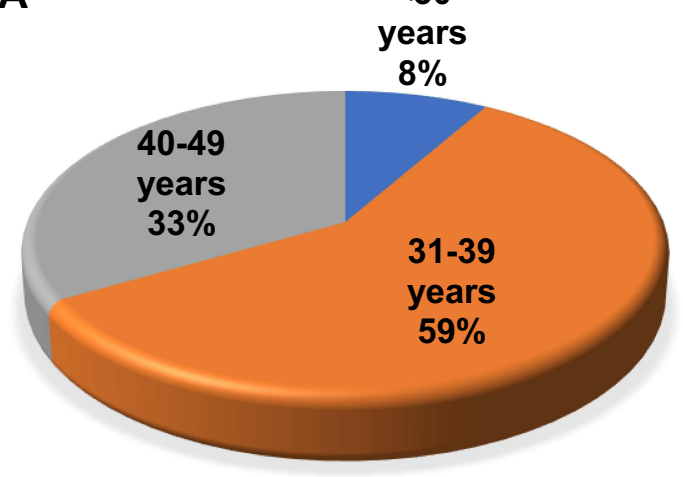

C

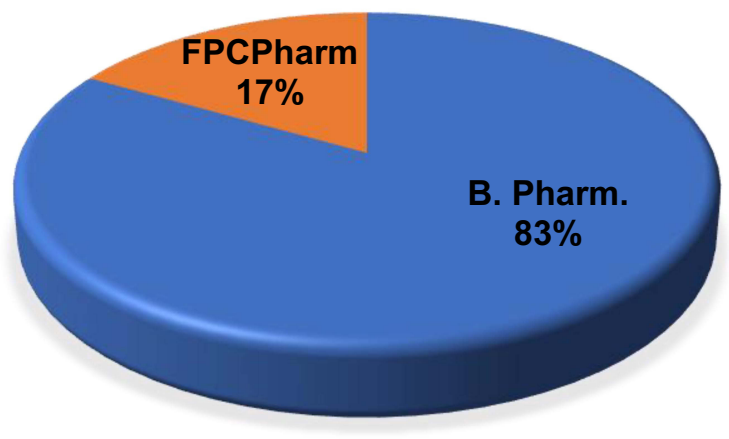

B

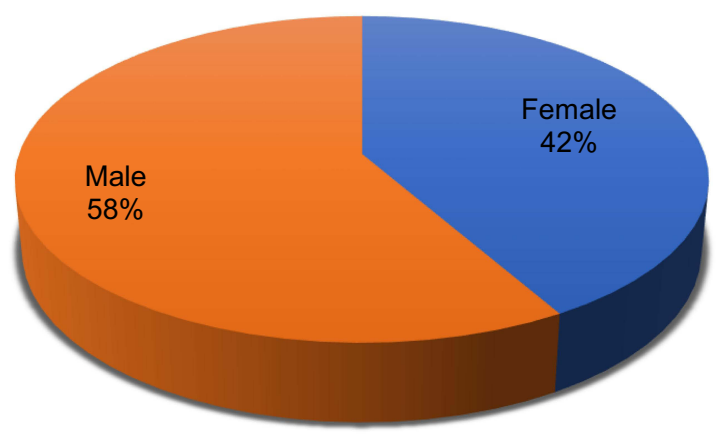

D

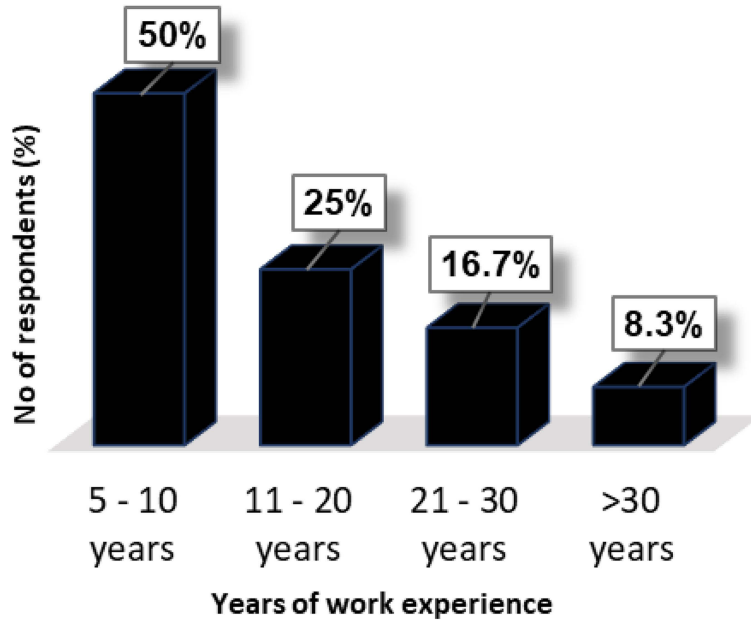

Figure I Socio-demographic profile of the participants showing (A) Age distribution, (B) Gender distribution (C) Highest professional educational qualification (D) Years of work experience.

Abbreviations: B Pharm, Bachelor of Pharmacy; FPCPharm, Fellowship of West African Postgraduate College of Pharmacy.

\section{Quantitative Assessment of Workplace} Teamwork

Quantitative data showed that the pharmacists are aware of, disposed to practice, and appreciate the benefits of teamwork in the hospital. They believed they are team players, and are comfortable participating in teamwork. They agreed that working as a team has positively affected the patients, and is for the overall good of the public. They stated that intradisciplinary team members share similar ideas about teamwork, understand each other's roles, and value members' expertise (Table 1).

Quantitative assessment to identify the factors that affect teamwork demonstrated that appreciation and value attached to individual's expertise by intradisciplinary team members, willingness to cooperate on new practices, and sharing of responsibilities and goals for patient care positively influence teamwork (Tables 2 and 3). However, they do not think actions of the hospital management promote teamwork. They revealed that poor interprofessional collaborative practices; existence of turf areas, so designated as no-go-areas by allied health care professionals in the interdisciplinary team; lack of opportunities to learn new skills through formal training; and poor remuneration are barriers to teamwork (Tables 2 and 3).

\section{Qualitative Assessment of Workplace Teamwork}

Results from the focus group discussions strongly corroborate the quantitative findings on the pharmacists' perceptions and lived experiences, and factors that influenced teamwork (Table 3) in their workplace. Thematic analysis of qualitative data revealed impediments to team work under three themes - 
Table I Awareness, Practices and Perceptions of Hospital Pharmacists About Teamwork

\begin{tabular}{|l|l|l|l|}
\hline \multirow{2}{*}{ Statement/Question } & \multicolumn{2}{|l|}{$\begin{array}{l}\text { Numerical } \\
\text { Response }\end{array}$} & \multirow{2}{*}{ Remark } \\
\cline { 2 - 4 } & Mean & SD & \\
\hline I am a team player. & 4.33 & 0.89 & Agree \\
\hline $\begin{array}{l}\text { I am comfortable participating in } \\
\text { teamwork. }\end{array}$ & 4.33 & 0.89 & Agree \\
\hline $\begin{array}{l}\text { My colleagues (pharmacists) and I do } \\
\text { share similar ideas about teamwork. }\end{array}$ & 4.00 & 0.60 & Agree \\
\hline $\begin{array}{l}\text { My colleagues (pharmacists) understand } \\
\text { the roles and responsibilities of all } \\
\text { intradisciplinary team members. }\end{array}$ & 3.58 & 1.24 & Agree \\
\hline $\begin{array}{l}\text { An individual's expertise is appreciated } \\
\text { and valued by intraprofessional team } \\
\text { members (ie, pharmacists). }\end{array}$ & 3.42 & 1.08 & Agree \\
\hline $\begin{array}{l}\text { My colleagues (pharmacists) are willing } \\
\text { to cooperate on new practices. }\end{array}$ & 3.67 & 0.65 & Agree \\
\hline $\begin{array}{l}\text { Do you feel that working as a team has } \\
\text { positively affected the patients/clients at } \\
\text { your workplace? }\end{array}$ & 3.67 & 0.98 & Agree \\
\hline $\begin{array}{l}\text { Health professionals working as a team } \\
\text { (intra- and interdisciplinary) is in the } \\
\text { public interest. }\end{array}$ & 4.25 & 1.22 & Agree \\
\hline $\begin{array}{l}\text { There is effective collaboration between } \\
\text { pharmacists and allied health care } \\
\text { professionals in the hospital }\end{array}$ & 1.08 & 0.29 & Disagree \\
\hline
\end{tabular}

Abbreviation: SD, standard deviation.

attitudes and behaviors of allied health care professionals, health system structure, and administrative factors (Table 4).

\section{Theme I: Attitudes and Behaviors of Allied Health Care Professionals}

Attitudes and behaviors of allied health care professionals, such as doctors' claim of ownership of patients, doctors' dominance, allied professionals' lack of knowledge and understanding of the role of pharmacists, other health professionals not amenable to professional judgements of pharmacists, turf protection and resistance by other professionals, and interdisciplinary rivalry were identified as impediments to multidisciplinary teamwork.

\section{Doctors' Claim of Ownership of Patients}

Participants stated that doctors see the patients as their own and not to be shared with any other health care professional.
Table 2 Quantitative Assessment of Factors That Influence Teamwork in the Workplace

\begin{tabular}{|l|l|l|l|}
\hline \multirow{2}{*}{ Statement/Question } & \multicolumn{2}{|l|}{$\begin{array}{l}\text { Numerical } \\
\text { Response }\end{array}$} & Remark \\
\cline { 2 - 4 } & Mean & SD & \\
\hline My workplace supports teamwork. & 2.33 & 1.03 & Disagree \\
\hline $\begin{array}{l}\text { There are turf areas that some } \\
\text { members of the interdisciplinary team } \\
\text { see as their territory. }\end{array}$ & 3.08 & 1.16 & Agree \\
\hline $\begin{array}{l}\text { Effective interdisciplinary collaborative } \\
\text { practices that promote teamwork exist } \\
\text { in the hospital }\end{array}$ & 1.17 & 0.39 & Disagree \\
\hline $\begin{array}{l}\text { The sharing of responsibilities and goals } \\
\text { for patient care provides opportunities } \\
\text { to promote teamwork at the } \\
\text { workplace. }\end{array}$ & 3.08 & 0.79 & Agree \\
\hline $\begin{array}{l}\text { Do you feel that your remuneration } \\
\text { reflects your worth to the team and by } \\
\text { extension the organization? }\end{array}$ & 2.33 & I.15 & Disagree \\
\hline $\begin{array}{l}\text { Do you feel that management actions or } \\
\text { inactions promote teamwork at your } \\
\text { workplace? }\end{array}$ & 2.92 & 1.24 & Disagree \\
\hline $\begin{array}{l}\text { Opportunities to learn new skills } \\
\text { through formal training are abundant in } \\
\text { my workplace. }\end{array}$ & 2.17 & 0.94 & Disagree \\
\hline
\end{tabular}

Abbreviation: SD, standard deviation.

The respondents believed this may be partly due to the training doctors received in school, and which they have carried over to their professional practice. Some respondents stated:

Medical doctors in particular, their orientation from their training is that they own the patient, they do not share the patient with any other professional. This perception is still dominant, probably they are still being taught so in medical school; and they act based on that perception, thereby technically excluding other professionals from contributing to patient care. They fail to see patient care as the work of every member of the health care team.

\section{Doctors' Dominance}

The respondents perceived that the resistance to teamwork exhibited by other professionals in the clinical team is partly attributable to doctor's dominance:

Doctors do not see health care services delivery as teamwork in Nigeria, they see it as fully under their authority (a 
Table 3 Factors Identified to Influence Teamwork in the Hospital

\begin{tabular}{|l|l|}
\hline Enabling Factors & Constraints \\
\hline Team member's proficiency & $\begin{array}{l}\text { Poor interprofessional } \\
\text { collaboration }\end{array}$ \\
\hline $\begin{array}{l}\text { Sharing of responsibilities and goals for } \\
\text { patient care }\end{array}$ & Existence of turf areas \\
\hline $\begin{array}{l}\text { Team members' appreciation of individual } \\
\text { colleague's expertise. }\end{array}$ & Interdisciplinary rivalry \\
\hline \multirow{2}{*}{$\begin{array}{l}\text { Understanding of the roles and } \\
\text { responsibilities of team members }\end{array}$} & Workplace policies \\
\hline Willingness to accept positive change & Defective leadership \\
\hline \multirow{2}{*}{$\begin{array}{l}\text { Appreciation that teamwork by health } \\
\text { professionals is essential for optimum } \\
\text { health care delivery }\end{array}$} & $\begin{array}{l}\text { Lack of adequate in- } \\
\text { service training }\end{array}$ \\
\cline { 2 - 3 } & Poor remuneration \\
\cline { 2 - 3 } & Salary disparity \\
\cline { 2 - 3 } & Poor communication \\
\hline
\end{tabular}

Table 4 Qualitative Assessment of Workplace Teamwork

\begin{tabular}{|l|l|}
\hline Theme & Subthemes \\
\hline $\begin{array}{l}\text { Theme I: Attitudes and } \\
\text { behaviors of allied health care } \\
\text { professionals }\end{array}$ & $\begin{array}{l}\text { Doctor's claim of ownership of } \\
\text { patients }\end{array}$ \\
\cline { 2 - 2 } & Doctor's dominance \\
\cline { 2 - 2 } & $\begin{array}{l}\text { Allied professionals' lack of } \\
\text { knowledge and understanding of } \\
\text { the role of pharmacists }\end{array}$ \\
\cline { 2 - 2 } & Interdisciplinary rivalry \\
\cline { 2 - 3 } & $\begin{array}{l}\text { Turf protection and resistance by } \\
\text { other health care professionals }\end{array}$ \\
\cline { 2 - 3 } & $\begin{array}{l}\text { Other health professionals not } \\
\text { amenable to professional } \\
\text { judgements of pharmacists }\end{array}$ \\
\hline Theme 2: Health system & $\begin{array}{l}\text { Uncharted practice territory for } \\
\text { pharmacists }\end{array}$ \\
\cline { 2 - 3 } structure & Disparity in remuneration \\
\hline Theme 3: Administrative & Poor communication \\
\cline { 2 - 3 } & $\begin{array}{l}\text { Resistance to change and new } \\
\text { ideas }\end{array}$ \\
\cline { 2 - 3 } & Workplace policies \\
\cline { 2 - 3 } & Defective leadership style \\
\hline
\end{tabular}

monopoly). They see other health care professionals as attendants, while they are the health care providers. This mindset does not encourage adequate contributions by other health professionals especially the pharmacists, in achieving the goal of patient care.

\section{Allied Professionals' Lack of Knowledge and Understanding of the Role of Pharmacists}

The pharmacists stated that allied health care professionals lack adequate knowledge and understanding of the role of pharmacists:

Occasionally, when the pharmacists try to engage the doctors, they do not want to carry pharmacists along. The doctors may not want to discuss the case; sometimes they complain that they do not understand what the pharmacists are doing, for example, in the ward.

The other health professionals say, "What is the pharmacist looking for in the ward"; and they complain that you are in the ward, they do not understand what you are doing.

\section{Other Health Professionals Not Amenable to Professional Judgements of Pharmacists}

Participants stated that other health professionals are not amenable to professional judgements/opinions of pharmacists:

If I have a patient whose prescription needs a review and I contact a doctor, the reply sometimes is, "pharmacist dispense as such".

On their part, nurses do not agree to effect changes on prescriptions until they get doctor's directives. The nurses give responses such as, "you don't have the right to correct me". So, such matters are unattended to.

Most times, doctors for example, do not even want to listen to the ideas of pharmacists. They will always want to impose their own ideas on the pharmacists.

In an effort to proffer solution to lack of teamwork among health care professionals, a participant suggested that respect for other's opinion is important:

If we can remove this idea and attitude of "I know more than you," I believe health professionals can work seamlessly as a team. Each person should try to see another's opinion as vital, and not to disregard it without due consideration. 


\section{Turf Protection and Resistance by Other Health Care Professionals}

Participants stated that some health professionals regard some duties as their traditional roles (territory/turf areas), and exhibit some resistance when others try to engage in those roles. This is typified by the fact that the doctors regard pharmacists going on clinical ward rounds as an encroachment into their territory, consequently they show resistance towards pharmacists going on clinical ward rounds:

Another issue is resistance from the doctors. When they see us in the ward, they say it openly, "what is the pharmacist looking for in the ward, what is the pharmacist doing here? we don't understand what you are doing in the ward".

\section{Interdisciplinary Rivalry}

Interdisciplinary rivalry among health care workers was also identified as a factor that hinders teamwork:

There is this caustic relationship, manifesting as rivalry and challenge, that some doctors feel or tend to perceive when pharmacists raise concerns about prescriptions (eg, drug dosage, drug interactions).

\section{Theme 2: Health System Structure}

Uncharted practice territory for pharmacists and disparity in remuneration due to nature of the health system structure were also identified as barriers to teamwork.

\section{Uncharted Practice Territory for Pharmacists}

Study findings revealed that in the concept of modern patient management, the roles of pharmacists especially in Nigerian public hospitals have not been clearly mapped out. The non-existence of charted practice territory for pharmacists is expressed by a respondent:

If I can be given the opportunity to work in the ward and put in my own skill as pharmaceutical care provider, that will augur well for improved health care delivery.

\section{Disparity in Remuneration}

The pharmacists spoke of the existence and impact of disparity in the remunerations of health care professionals. They believed that their remuneration is not commensurate with the value they add to the health care team:

There is disparity in remuneration of health care professionals, with some earning significantly higher than those from a different profession. Consequently, there is demotivation of those earning less and you see people showing grievances here and there.

\section{Theme 3: Administrative Factors}

Administrative factors such as poor communication, resistance to change and new ideas, workplace policies, and defective leadership style were also identified to hinder teamwork.

\section{Poor Communication}

Poor communication among health care professionals was also identified to exert a negative influence on teamwork:

There is lack of effective communication among health care professionals. It's (communication) a two-way thing. When there is inadequate communication, then there is laxity in the team working as one; that, I have experienced.

The importance of good communication in teamwork was reiterated by another respondent:

Once communication flows among the parties; when I see a challenge, I raise it and someone takes it up and acts on the issue that I have raised, we will be able to achieve something. This has worked every time I have done that.

\section{Resistance to Change and New Ideas}

Some respondents identified resistance to change as a barrier to effective teamwork:

There is usually resistance to change, especially when one is used to a particular system in a certain way. Change is usually difficult, even if it is to improve on the existing format or ways. People are usually resistant to trying a new approach.

Doctors or nurses will tell the pharmacist, "This is how it has been"; they do not want to alter the status quo.

One of the respondents suggested:

I think it is a mindset or attitude problem. We just need to be open minded, to know that someone may come with a better way of doing what we are already used to doing and be open to such changes.

\section{Workplace Policies}

According to them, the workplace does not have requisite policies, organizational structures and personnel development programs to promote teamwork. They said that the 
hospital management does not conduct appropriate orientation and training of all health care providers geared towards promoting teamwork. Moreover, they stated that to a large extent, existing policies are favorable to some subset(s) of health care professionals, and unfavorable to some. This situation is worsened by difficulty in amending defective policies.

Some policies that govern the health care operations in Nigeria are not equitable. These policies have technically excluded pharmacists as well as some other health care professionals from being adequately and optimally involved in patient care.

It is very difficult to alter or amend the defective policies because some people or beneficiaries of that lopsidedness or imbalance in some government policies on the health care system seem to be resistant to any alteration, even though they know from experience in other countries that is not how it is done. Secondly, because they have enjoyed the monopoly of such practice for a long time, they are resistant to any form of change (even if it is positive and progressive).

\section{Defective Leadership Style}

Respondents also stated that defective leadership style existing in the workplace does not promote teamwork:

My personal opinion is that we do not have effective leadership, also those in positions of authority do not exhibit leadership qualities necessary to efficiently manage and harness the highly trained health care professionals on ground.

For teamwork to work in health sector we need to change leadership structure and style. We need non-biased leaders to handle the sector. Members of one health profession should not be administrators/leaders/in-charge of a health facility. Health care institutions ought to be managed by somebody who respects the view of others, respects other people's profession, and believes in quality management in everything done, even cleaning. So, we need policy makers to focus on that as number one priority.

If we have people with open mindset, who are in policy making and implementation positions, and are aware of the essence of teamwork in health care delivery, I think the problem of rancor among health care professionals will become history in our health care system.

So, for teamwork to "work" we have to start from the leadership, since they are involved in policy making.
A pharmacist who had opportunity to work in a subsection of the hospital partly managed by a nongovernmental organization (with a better leadership) explained:

Looking at the two units I have worked (in), and compared with where I am now, I had cordial relationship with other health care providers, the leadership were actually forward-looking. They would unite together, promote avenues where everybody come together and share suggestions and recommendations. They will actually listen, sit down and take decisions and put them into practice; that really helped us to work together as a team.

\section{Discussion}

A synthesis of the findings from both quantitative and qualitative assessments revealed that though the hospital pharmacists are aware of and appreciate teamwork, there are impediments to interprofessional teamwork. Various studies have shown that though teamwork by health care professionals is essential to achieve optimum health care services delivery, its practical realization has been limited. ${ }^{3,13}$

Results of this study demonstrated that poor interdisciplinary collaborative practices (doctors' dominance and claim of ownership of patients, disregard for professional opinions of others, etc.) impede teamwork in health care services delivery. Since the mode of education and training of Nigerian health care professionals was identified by the respondents as a contributing factor, albeit partly, to the poor interdisciplinary collaborative practices, there is need to incorporate the tenets of teamwork in their curriculum. The current method of education of health care professionals in Nigeria hinders the graduate's ability to engage in collaborative practices and teamwork in order to ultimately provide holistic and patient-centered care. Health care delivery in Nigeria is carried out by various professionals who because of educational silos in their training have diverse perceptions, beliefs, and attitudes towards each other. The educational silos teach students in isolation from or even in competition with each other, thereby producing cocooned social graduates who are not only unacquainted with the roles of other professions in the health care team, but may also have adverse preconceptions and perceptions about them. Consequently, there is fraught and combative rather than constructive and effective relationships among the health care professionals, clan-culturalization and turf battles, ${ }^{27}$ which if not 
checkmated over time gets ingrained in their daily activities and may ultimately mold their work and relationship culture. Effective interprofessional education has been demonstrated to result in effective collaborative practices and teamwork. ${ }^{5,6,28,29}$ We propose that principles and practices of teamwork be incorporated in the curriculum of education of all health care professionals to prepare students and potential graduates to engage in effective interprofessional collaborative practices.

The hospital pharmacists stated that allied professionals have a poor understanding of the roles of pharmacists in health care cum modern patient management, thereby diminishing their relevance in the clinical team. This lack of clarity and understanding of pharmacist's roles and functions by allied professionals is perceived by pharmacists as "resistance to their presence"; on the other hand, pharmacists performing certain roles is perceived by some other professionals as a "threat." The consequences of these include rivalry, disharmony, rancor, and lack of team spirit. This correlates with the observations of pharmacists in this study that interdisciplinary rivalry is a barrier to teamwork in their workplace. Other health care professionals and the public are largely unaware of the changing and expanding professional expertise and roles of pharmacists and continue to underutilize them because they still see the pharmacists' role in health care as mainly a dispensing service. Besides dispensing medicines, the pharmacist's unique expertise includes pharmaceutical care, including medication therapy management and rational drug use; drug and health care information; access to care; and prevention services, among others. ${ }^{11}$ Therefore, pharmacists ought to be duly recognized as integral members of a health care team, to fully harness and maximize their potentials, contributions and benefits to the team. Hitherto, poor understanding of the roles of team members has been demonstrated to negatively impact on the functionality of the health care team, and stunt the evolution and innovations of interprofessional education and practice. ${ }^{30}$ To provide the essential framework needed to take advantage of each team member's clinical skills and promote a cohesive and collaborative teamwork approach to health care, it is absolutely imperative that all interdisciplinary team members are knowledgeable about each other's roles, responsibilities, and level of accountability at the team, unit and the organization as a whole.

Respondents also stated that other health professionals are not amenable to professional judgements/opinions of pharmacists, which maybe attributable, albeit partly to lack of knowledge and understanding of the roles of pharmacists in modern patient management. This observation suggests lack of due recognition of pharmacists by other professionals, and paucity of mutual trust and respect. This attitude exhibited by allied health care professionals may lead to inadequate and inappropriate attention been given to some matters, thereby adversely affecting patient care. To ensure optimum patient care and patient safety, health care providers need to exchange, consider, examine and review a considerable amount of information. ${ }^{31,32}$ As medication specialists, pharmacists provide or evaluate much of the information used by doctors and nurses, in addition to providing information to patients. Research has demonstrated that addition of a pharmacist in a collaborative, team-based setting can improve performance against quality indicators and national health goals. ${ }^{33}$ If professional contributions of pharmacists are disregarded by allied professionals, the consequence is suboptimal health care services. So, full integration and participation of pharmacists in health care teams is gold standard for optimum health care delivery.

Though participants agreed that sharing of responsibilities and goals for patient care provides opportunities to promote workplace teamwork, they stated that there are turf areas (traditional roles) that some allied professionals regard as their territory and consider performance of those roles by others as a threat and incursion into their territory. The observation that doctors and nurses regard the presence of pharmacists in the wards as an encroachment into their territory, suggest that some health professionals see evolved new roles of other allied disciplines as an encroachment, with resultant resistance. Adapting to changing conditions is an element of teamwork; professionals ought to accept and adapt to changes in the constantly evolving health care landscape, and not cling to obsolete ways. Moreover, teamwork may involve overlap of proficiencies, so each team member ought to accommodate interdisciplinary collaborative practices to achieve the team's unified goal.

Interdisciplinary rivalry among health care professionals was also identified as an impediment to teamwork. In an effort to proffer solution to the existing interdisciplinary rivalry among health care professionals, a participant suggested mutual respect for other team members and their opinions. To achieve effective teamwork in health care delivery, an interdisciplinary team coherently bound by shared goals, mutual respect, trust, 
open and collaborative interdependency is essential. $^{2,4,34,35}$ The resistance shown by other professionals to the participation of pharmacists in the team creates the impression that they are not wanted, and their expertise and opinions are not relevant. This creates a sense of alienation and irrelevance that breeds resentments, negativism and misunderstandings with adverse behavioral outcomes (since beliefs and behaviors are interrelated). The resultant effect is a health care team without a team spirit, which will have a negative impact on practice structure and team processes at the workplace. Proper integration of all team members will increase each individual's awareness of potential roles and benefits of respective members to the entire team, so that team members (pharmacists, nurses, physiotherapists, doctors, etc.) could play a part in and benefit from working together as a team. ${ }^{36}$

Tied to turf protection and resistance exhibited by other professionals, is uncharted territory for Nigerian pharmacists and the fact that their proficiency is far above the currently defined roles for pharmacists in Nigerian health care sector; this is a national health system policy matter that should be handled by the Nigerian government at the appropriate higher level. Various studies have demonstrated that clinical interventions and other health care services provided by pharmacists reduce the risk of potential adverse drug events and health care costs, and also improve patient outcomes. ${ }^{11,33}$ Earlier studies have identified unclear definition of roles and poorly defined processes as barriers to establishing and sustaining effective teamwork. ${ }^{4,7}$ Worldwide, pharmacists are working in clinically advanced roles, and it is pertinent that Nigeria joins the trend. Through transdisciplinary approaches involving teamwork, the Nigerian pharmacist's contribution to health care will aid in achieving optimal health outcomes.

The pharmacists also strongly perceived that their remuneration is not commensurate with the value added to the team and by extension the organization. Remuneration refers to monetary or financial benefits that is accrued or given to an employee as a result of services rendered, commitment to the organization, or reward for employment. ${ }^{37-39}$ Employee remuneration serves to boost morale, increase motivation and promote team cohesion. Good remuneration improves productivity; while poor remuneration reduces motivation and morale of workers, ultimately reducing productivity. ${ }^{37-39}$ Furthermore, the long-established notion that individuals care about not only their own salary, but also their salary relative to that of their co-workers ${ }^{40,41}$ has implications for interprofessional teamwork. Remuneration and pay disparity have significant impact on the attitude and performance of workers in an organization. Salary inequality among different health care professionals in Nigeria has significantly hindered teamwork; this has strongly manifested in the incessant industrial actions by health care professionals. The existing disparity in the remuneration of health care professionals leads to poor team cohesion, with the attendant adverse effects on performance and patient outcomes.

Poor communication among health care professionals was also identified to exert a negative influence on teamwork. Communication improves the relationships among team members, making them feel comfortable, satisfied, and motivated at work. Components of communication include listening with understanding, demonstrating effective relationships, verbal and visual communication, and use of factual information (eg, data), among others. ${ }^{42}$ Effective communication is an essential component of teamwork, ${ }^{43}$ as it reduces the chances of conflicts and promotes understanding and cohesion among team members. Various studies have demonstrated that the promotion of teamwork in health care sector hinges on understanding, effective communication, information sharing and education of health care workers on their expected roles in current health care services delivery trends. ${ }^{4,73}$ If communication in the workplace is poor and ineffective, workers are less likely inclined to collaborate with each other. Consequently, there is poor teamwork which may potentially lead to friction and rivalry among workers, as is obtained in Nigerian health care system. Since the health professionals in a facility are the core staff, paucity of camaraderie and strong working relationships would significantly reduce outcomes.

The findings of this study revealed that the public health institution lacked requisite policies, organizational structures and personnel development programmes to promote teamwork. Periodic training of health care professionals, aimed at improving interdisciplinary collaborative practices should be pursued by health institutions. In line with global trends, health care needs of the populace, and evolving roles of health care professionals, the Nigerian government should reappraise and modify various health care system policies in the country to achieve optimum health care delivery to the citizens.

Respondents also stated that defective leadership existing in the workplace is a barrier to teamwork. 
Leadership and management competencies are identified as key elements for improved health care systems. ${ }^{44,45}$ The existence of competent managers at all levels is very important to handle the challenges and improve the constantly changing health sector. Competence is a tool used to optimize performance in an organization, and it comprises a set of knowledge, skills and ability required to perform a given task. ${ }^{42,46}$ According to The National Center for Health Care Leadership (NCHL), leaders in health organizations are expected to possess certain leadership and management competences spread across three competency domains namely people, execution, and transformation. ${ }^{47}$ People refers to the organizational atmosphere where employees are valued irrespective of backgrounds and provides a motivating environment for them to excel; execution is about transforming vision and strategy into optimal institutional performance; and transformation is visioning, energizing, and stimulating a change process that unites communities, patients, and professionals around new models of health care and wellness. ${ }^{47,48}$ Seven key competency subdomains further identified to be essential for functional leadership and management roles in health care settings are communication, professionalism, managing change, relationship building, analytical thinking, leadership, and innovative thinking. ${ }^{42}$ It is pertinent to note that the factors identified in this study to influence teamwork fall into and correlate with these identified domains and subdomains. This strongly underlines the importance of recruiting competent leaders and managers in the health sector. Also, regular on-the-job training and refresher courses on these competencies will improve the capabilities of leaders and managers in the health care sector. Where competent and understanding leadership is appropriately mixed with the right policies, there is general trust and unity of purpose among everyone. The presence of trust creates an atmosphere of cordiality, care, and opportunity for selfdevelopment. ${ }^{49}$ Where there is cordiality, trust and mutual respect; there is improved relationship among team members, flow of information and communication, roles are shared properly, and teamwork thrives.

\section{Limitation of the Study}

The study was conducted in one tertiary hospital.

\section{Conclusion}

Though the hospital pharmacists demonstrated good understanding of, positive disposition to participate in, and awareness of the benefits of teamwork; they identified some factors that hinder multidisciplinary teamwork in the hospital. To prepare health care professionals to participate effectively in multidisciplinary teams, the principles and practices of teamwork should be incorporated in the curriculum of each discipline. Interdisciplinary collaborative practices, health system structure, institutional policies and leadership should be strengthened to enhance teamwork. In order to improve health care services delivery in Nigeria, health system authorities and individual professionals should strive to strengthen the enabling factors and remove the barriers to teamwork.

\section{Data Sharing Statement}

The data generated during the study are available from the corresponding author on reasonable request.

\section{Ethics Approval and Consent to Participate}

The study was approved by the Institutional Review Board of Walden University (No: 01-23-19-0358776) and the Institute Review Board Committee of the Nigerian Government-owned health facility (NHA/EC/091/2018), and was carried out according to ethical guidelines stipulated by both institutions. All participants provided written and signed informed consent, which included publication of anonymized responses.

\section{Acknowledgments}

We are grateful to our research assistants for supporting data collection; to Dr. Ayola Arowolo for assistance in analyzing the data; and to all study participants. The abstract of this paper was presented as a doctoral dissertation, ${ }^{22}$ available by following the link: https://scho larworks.waldenu.edu/cgi/viewcontent.cgi? article= 9679\&context $=$ dissertations.

\section{Author Contributions}

All authors made a significant contribution to the work reported, whether that is in the conception, study design, execution, acquisition of data, analysis and interpretation, or in all these areas; took part in drafting, revising or critically reviewing the article; gave 
final approval of the version to be published; have agreed on the journal to which the article has been submitted; and agree to be accountable for all aspects of the work.

\section{Disclosure}

The authors report no conflicts of interest in this work.

\section{References}

1. Salas E, Dickinson TL, Converse SA, et al. Toward an understanding of team performance and training. In: Swezey RW, Salas E, editors. Teams: Their Training and Performance. Norwood, NJ: Ablex; 1992:3-29.

2. World Health Organization. Being an effective team player; 2012. Available from: http://www.who.int/patientsafety/education/curricu lum/who_mc_topic-4.pdf. Accessed August 29, 2019.

3. Bryant R, Chaar B, Schneider C. Differing clinical pharmacy service models: quantitative and qualitative analysis of nurse perceptions of support from pharmacists. Int J Nurs Stud. 2018;86:96-98. doi:10.1016/j.ijnurstu.2018.04.003

4. Oandasan I, Baker GR, Barker K, et al. Teamwork in Health Care: Promoting Effective Teamwork in Health Care in Canada, Policy Synthesis and Recommendations. Canadian Health Services Research Foundation; 2006. Available from: https://www.research gate.net/publication/249940003_Teamwork_in_Healthcare Promoting_Effective_Teamwork_in_Healthcare_in_Canada.

Accessed December 15, 2021.

5. World Health Organization. Framework for Action on Interprofessional Education and Collaborative Practice. Geneva; World Health Organization; 2010:7. Available from: http://whqlib doc.who.int/hq/2010/WHO_HRH_HPN_10.3_eng.pdf. Accessed August 23, 2019.

6. Kalb KA, O'conner-von S. Strategies in education: breaking down silos, building up teams. Health Prog. 2012;93(3):39-45.

7. Babiker A, El Husseini M, Al Nemri A, et al. Health care professional development: working as a team to improve patient care. Sudan J Paediatr. 2014;14(2):9-16.

8. Adams ML, Blouin RA. The role of the pharmacist in health care: expanding and evolving. $N C$ Med J. 2017;78(3):165-167. doi:10.18043/ncm.78.3.165

9. American Public Health Association (APHA). The role of the pharmacist in public health. APHA 2006, APHA Policy 200614. Available from: https://www.apha.org/policies-and-advocacy/publichealth-policy-statements/policy-database/2014/07/07/13/05/the-roleof-the-pharmacist-in-public-health. Accessed December 23, 2021.

10. Calvert RT. Clinical pharmacy: a hospital perspective. $B r J$ Clin Pharmacol. 1999;47(3):231-238. doi:10.1046/j.13652125.1999.00845.x

11. Dalton K, Byrne S. Role of the pharmacist in reducing health care costs: current insights. Integr Pharm Res Pract. 2017;6:37-46. doi:10.2147/IPRP.S108047

12. Jeffs L, Abramovich I, Hayes C, et al. Implementing an interprofessional patient safety learning initiative: insights from participants, project leads and steering committee members. BMJ Qual Saf. 2013;22(11):923-930. doi:10.1136/bmjqs-2012-001720

13. Pannick S, Beveridge I, Wachter RM, et al. Improving the quality and safety of care on the medical ward: a review and synthesis of the evidence base. Eur J Intern Med. 2014;25(10):874-887. doi:10.1016/ j.ejim.2014.10.013

14. Institute of Medicine Committee on Quality of Health Care in America. Crossing the Quality Chasm: A New Health System for the 21st Century. Washington DC: New Academy Press; 2001.
15. Institute of Medicine (US) Roundtable on Evidence-based Medicine. The Healthcare Imperative: Lowering Costs and Improving Outcomes. In: Yong P, Saunders RS, Olsen L, editors. Washington (DC): National Academic Press (US); 2010.

16. Mayo AT, Woolley AW. Teamwork in health care: maximizing collective intelligence via inclusive collaboration and open communication. AMA J Ethics. 2016;18(9):933-940.

17. Rosen MA, DiazGranados D, Dietz AS, et al. Teamwork in healthcare: key discoveries enabling safer, high quality care. Am Psychol. 2018;73(4):433-450. doi:10.1037/amp0000298

18. Uneke C, Ogbonna A, Ezeoha A, et al. Innovative Health Research Group. The Nigeria health sector and human resource challenges. Internet J Health. 2007;8:1.

19. Bakare AS, Olubokun S. Health care expenditure and economic growth in Nigeria: an empirical study. $J$ Emerg Trends Econ Manage Sci. 2011;2(2):83-87.

20. Welcome MO. The Nigerian health care system: need for integrating adequate medical intelligence and surveillance systems. $J$ Pharm Bioallied Sci. 2011;3(4):470-478. doi:10.4103/0975-7406.90100

21. Erhabor O, Adias TC. Harmony in health sector: a requirement for effective health care delivery in Nigeria. Asian Pac J Trop Med. 2014;7(Suppl 1):S1-S5. doi:10.1016/S1995-7645(14)60 196-6

22. Mohammed E Perceptions of Public Sector Pharmacists Regarding Their Beliefs, Attitudes Towards Teamwork [dissertation]. Baltimore Md: Walden University; 2020. Available from: https://scholarworks. waldenu.edu/cgi/viewcontent.cgi? article $=9679 \&$ context $=$ disserta tions. Accessed December 15, 2021.

23. Creswell JW. Research Design: Qualitative, Quantitative, and Mixed Methods Approaches. 3rd ed. Los Angeles: SAGE; 2009.

24. Creswell JW. Qualitative Inquiry \& Research Design: Choosing Among Five Approaches. 3rd ed. Los Angeles: SAGE; 2013.

25. Patton MQ. Qualitative Research and Evaluation Methods: Integrating Theory and Practice. 4th ed. Thousand Oaks, CA: SAGE; 2015.

26. Ames H, Glenton C, Lewin S. Purposive sampling in a qualitative evidence synthesis: a worked example from a synthesis on parental perceptions of vaccination communication. BMC Med Res Methodol. 2019;19:26. doi:10.1186/s12874-019-0665-4

27. Iles V. The challenges of leading professionals. Int J Public Serv. 2014;10(1):44-51. doi:10.1108/IJLPS-12-2013-0033

28. Reeves S, Perrier L, Goldman J, et al. Interprofessional education: effects on professional practice and healthcare outcomes (update). Cochrane Database Syst Rev. 2013;2013(3):CD002213. doi:10.1002/ 14651858.CD002213.pub3

29. Rhodes J, Winder P, Stratheran M, McMillan M, Richter K, McLeod M. Breaking down educational silos. Nurs N Z. 2016;22 (1):16-17.

30. Hickey EL, Dumke EK, Ballentine RL, et al. Prospective health students' perceptions of the pharmacist role in the interprofessional team. $J$ Interprof Care. 2018;32(2):250-253. doi:10.1080/ 13561820.2017.1381671

31. Stowasser DA, Allinson YM, O'Leary M. Understanding the medicines management pathway. J Pharm Pract Res. 2004;34 (4):293-296. doi:10.1002/jppr2004344293

32. O’Daniel M, Rosenstein AH. Professional communication and team collaboration. Hughes R, editor. In: Patient Safety and Quality: An Evidence-Based Handbook for Nurses. Rockville, MD: Agency for Healthcare Research and Quality (US); 2008. 1-14. Available from: https://www.ncbi.nlm.nih.gov/books/NBK2637/.: Accessed May 13, 2020 .

33. American Pharmacists Association (APhA). The role of pharmacists in a changing health care environment; 2017. Available from: https:// www.pharmacist.com/article/role-pharmacists-changing-health-careenvironment. Accessed August 3, 2019. 
34. Hall P, Weaver L. Interdisciplinary education and teamwork: a long and winding road. Med Educ. 2001;35(9):867-875. doi:10.1046/ j.1365-2923.2001.00919.x

35. Morley L, Cashell A. Collaboration in health care. J Med Imaging Rad Sci. 2017;48(2):207-216. doi:10.1016/j.jmir.2017.02.071

36. Makowsky MJ, Schindel TJ, Rosenthal M, et al. Collaboration between pharmacists, physicians and nurse practitioners: a qualitative investigation of working relationships in the inpatient medical setting. J Interprof Care. 2009;23(2):169-184. doi:10.1080/ 13561820802602552

37. Maicibi NA. Pertinent Issues in Management: Human Resource and Educational Management. 1st ed. Kampala: Net Media Publishers; 2005.

38. Ojeleye YC. The impact of remuneration on employees' performance: a study of Abdul Gusau Polytechnic, Talata-Mafara and State College of Education Maru, Zamfara State. Arab J Business Manage Rev. 2017;4(2):34-43. doi:10.12816/0037554

39. Muchai HW, Makokha EN, Namusonge G. Effects of remuneration system on organizational performance of teachers' service commission, Kenya. Eur J Business Manage. 2018;10(11):132-141.

40. Breza E, Kaur S, Shamdasani Y The morale effects of pay inequality. National Bureau of Economic Research. Working Paper No. 22491. 2016. Available from: https://www.nber.org/papers/w22491.pdf. Accessed August 3, 2019.

41. Breza E, Kaur S, Shamdasani Y. The morale effects of pay inequality. Q J Econ. 2018;133(2):611-663. doi:10.1093/qje/qjx041

42. Dorji K, Tejativaddhana P, Siripornpibul T, et al. Leadership and management competencies required for Bhutanese primary health care managers in reforming the district health system. J Healthc Leadersh. 2019;11:13-21. doi:10.2147/JHL.S195751
43. Davis C. Teamwork and the patient care experience. Nurs Made Incred Easy. 2017;15(5):4. doi:10.1097/01.NME.0000525557.44656.04

44. de Savigny D, Adam T. Systems Thinking for Health Systems Strengthening. Alliance for Health Policy and Systems Research. Geneva: World Health Organization; 2009. Available from: https:// apps.who.int/iris/bitstream/handle/10665/44204/9789241563895 eng.pdf;jsessionid=459ECE01E01748CA30E56D74BFF66259? sequence=1. Accessed August 2, 2019.

45. Vriesendorp S, Shukla M, Lassner KJ, et al. Health Systems in Action: An eHandbook for Leaders and Managers. Cambridge, MA: Management Sciences for Health; 2010. Available from: https://www.msh.org/resources/health-systems-in-action-anehandbook-for-leaders-and-managers. Accessed May 13, 2020.

46. Lekshmi P, Radhika R. Competency management as a strategy for performance appraisal. J Chem Pharm Sci. 2016;9(4):1909-1912.

47. National Center for Health Care Leadership (NCHL). National center for healthcare leadership competency model: NCHL. 2010:005-2010. Available from: http:/www.nchl.org/Documents/NavLink/Competency_ Model-summary_uid31020101024281.pdf. Accessed August 3, 2019.

48. McClesky JM. Situational, transformational, and transactional leadership and leadership development. J Bus Stud Q. 2014;5(4):117-130.

49. Dóci E, Stouten J, Hofmans J. The cognitive-behavioral system of leadership: cognitive antecedents of active and passive leadership behaviors. Front Psychol. 2015;6:1344. doi:10.3389/fpsyg.2015.01344
Integrated Pharmacy Research and Practice

\section{Publish your work in this journal}

Integrated Pharmacy Research and Practice is an international, peerreviewed, open access, online journal, publishing original research, reports, reviews and commentaries on all areas of academic and professional pharmacy practice. This journal aims to represent the academic output of pharmacists and pharmacy practice with particular focus on integrated care. All papers are carefully peer reviewed to ensure the highest standards as well as ensuring that we are informing and stimulating pharmaceutical professionals. The manuscript management system is completely online and includes a very quick and fair peer-review system, which is all easy to use. Visit http://www.dovepress.com/testimonials.php to read real quotes from published authors. 